\title{
Bifunctional magnesium oxide crystal successively as adsorbent and matrix modifier for preconcentration and determination of arsenic by graphite furnace atomic absorption spectrometry
}

\author{
Wang Qiang ${ }^{\mathrm{a}}$, Yu Zhuanni ${ }^{\mathrm{a}}$, Lan Jing ${ }^{\mathrm{a}, *}$, Liu Aifeng ${ }^{\mathrm{b}}$, Tian Yong ${ }^{\mathrm{b}, *}$ \\ a College of Chemistry and Pharmaceutical, Qingdao Agriculture University, Qingdao 266109, PR China \\ b CAS Key Laboratory of Bio-based Materials, Qingdao Institute of Biomass Energy and Bioprocess Technology, Chinese Academy of Sciences, Qingdao 266101, PR China
}

\section{A R T I C L E I N F O}

\section{Article history:}

Received 17 July 2016

Received in revised form 5 April 2017

Accepted 5 April 2017

Available online 6 April 2017

\section{Keywords:}

Arsenic

Atomic absorption spectrometry

Preconcentration

Magnesium oxide crystal

Bifunctional adsorbent

\begin{abstract}
A B S T R A C T
A novel method for determination of total inorganic arsenic in water samples, based on magnesium oxide crystals quantitatively preconcentration and graphite furnace atomic absorption spectrometry (GFAAS) detection has been developed. As the $\mathrm{MgO}$ crystals could successively act as the adsorbent and matrix modifier, the method presents great potential in practical routine analysis of inorganic arsenic. With optimization of the experimental conditions, $1.5 \mathrm{mg}$ of $\mathrm{MgO}$ was added into $4.0 \mathrm{~mL}$ water sample and ultrasonic dispersing $15 \mathrm{~min}$ for adsorbing the arsenic at first. Then, the mixture was centrifuged 5 min for separating the adsorbents and the water solution; the deposits were collected and dissolved with $\mathrm{HNO}_{3}$ for arsenic determination. The enrichment factor of 13 , limit of detection (LOD) of $0.087 \mu \mathrm{g} \mathrm{L}^{-1}$, relative standard deviation (RSD) of $4.5 \%\left(n=7, c=2.0 \mu \mathrm{g} \mathrm{L}^{-1}\right)$ were achieved under the optimized conditions. The procedure was validated by analysis of certified water sample (GBW08605), which results in good agreement between the certified and the found values. The method was further demonstrated for analysis of lake water, snow water and tap water, and satisfactory spiked recoveries of $98.5 \%$ to $103.0 \%$ were achieved for these samples. These preliminary results indicated the present method was practical and accurate for analysis of trace-arsenic in natural water samples.
\end{abstract}

(c) 2017 Elsevier B.V. All rights reserved.

\section{Introduction}

Arsenic in drinking water has caused severe health problems in many areas of the world, including South Asia, Middle of China, West of the USA, Mexico and Argentina, and even worse in developing countries and areas with low level of medical treatment and cognitive ability [1-3]. Millions of people are suffering the chronic poisoning and carcinogenic effects of arsenic. Melanosis, keratosis peripheral neuropathy, diabetes, ischemic heart disease, and impairment of liver function are commonly occurred with long-term exposing to the polluted drinking water [4-7]. Although the arsenic in drinking water has aroused the world wide attentions, and WHO (World Health Organization) has pointed out the maximum arsenic concentration of $10 \mu \mathrm{L} \mathrm{L}^{-1}$ as the provisional guideline value in the guidelines for drinking-water quality [8], the drink water arsenic problems especially in the developing countries/areas are still unsolved because of insufficient understanding of the arsenic pollution levels $[3,4,9]$. At present, the detection and notification of the arsenic levels in these polluted areas are even more urgent than other remedial measurements. Consequently, the economic and practical arsenic detection methods are highly necessitated [10-13].

\footnotetext{
* Corresponding authors.

E-mail addresses: m13295322818@163.com (J. Lan), tianyong@qibebt.ac.cn (Y. Tian).
}

In natural waters, the arsenic is mostly inorganic, i.e., arsenate and arsenite ions, denoted as $\mathrm{As}(\mathrm{V})$ and $\mathrm{As}(\mathrm{III})[1,14]$. However, the $\mathrm{As}(\mathrm{III})$ is unstable and rapidly converted to $\mathrm{As}(\mathrm{V})$ under ambient conditions [15]. The common methods for $\mathrm{As}(\mathrm{V})$ detection are atomic spectrometry methods, such as graphite furnace/electrothermal atomic absorption spectrometry (GFAAS/ETAAS) [16-18], hydride generation atomic fluorescence spectrometry (HGAFS) [19-23] and inductively coupled plasma mass spectrometry (ICPMS) [24-26]. The ICPMS provides the best sensitivity and accuracy among all the commercial detectors, but its high price and maintenance cost is still unaffordable for routing analysis in the developing countries and areas $[10,11,27,28]$. The GFAAS and HGAFS are more economic and would also provide accurate results while detecting clean samples with no/low level of interference ions [10,29]. The GFAAS and HGAFS methods require adding matrix modifier and hydride generation reagents for each sample detection, respectively. Because the limits of quantitation of arsenic by GFAAS and HGAFS are close to the suggested values of WHO $\left(10 \mu \mathrm{g} \mathrm{L}^{-1}\right)$ for the real water samples, the AAS and AFS cannot be directly used for arsenic determination in real drink water. The preconcentration and separation of arsenic in the water samples are necessary for the GFAAS and HGAFS methods $[16,19,23,30]$.

To date, solid-phase extraction (SPE) [23,31,32], liquid-liquid extraction [33-35], cloud point extraction [30,36,37], co-precipitation [38] and atom/hydride trapping [39-41] have been established for arsenic 

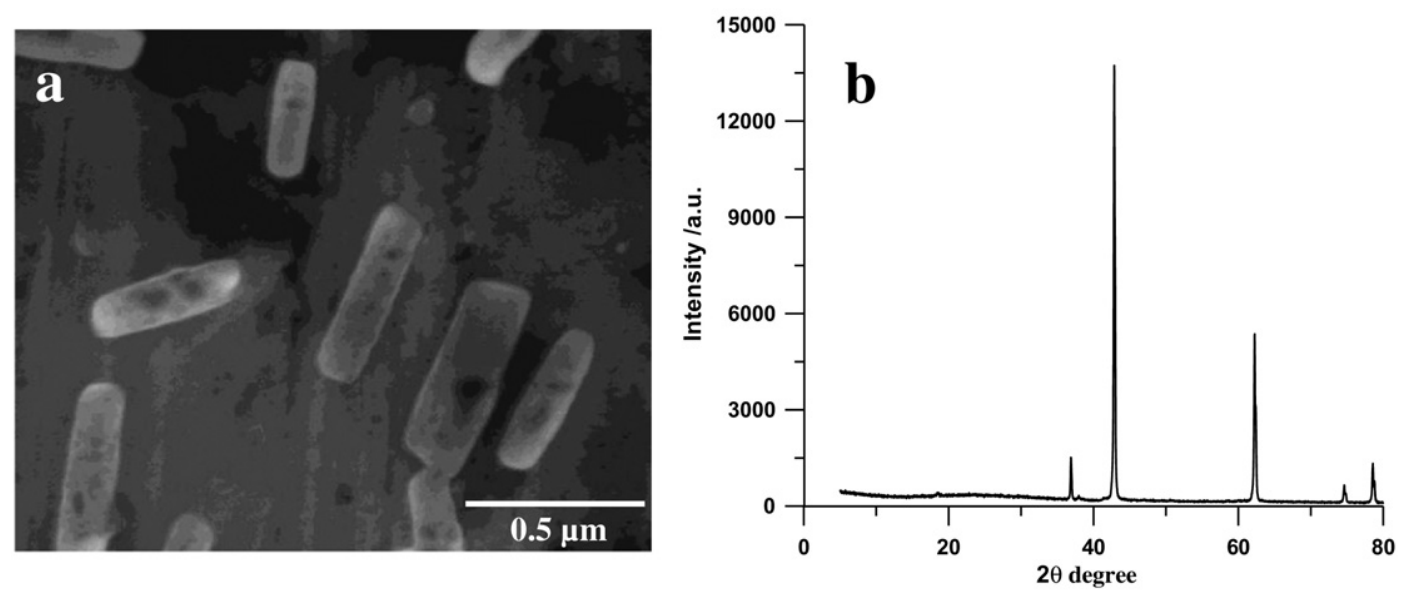

Fig. 1. SEM image (a) and the XRD pattern (b) of the MgO crystal particles.

preconcentration and determination. Recently, Chen et al. has invented a series of SPE methods for arsenic enriching and analytical performance improving of GFAAS and HGAAS, the adsorbents including akaganeite decorated graphene oxide composite [22], branch-polyethyleneimine modified carbon nanotubes [42] and esterified egg-shell membrane [43] were investigated for arsenic preconcentration, respectively. As a result, the limits of detection of HGAFS and GFAAS were significantly improved to tens nanogram per liter. Arsenic in snow, rain, pond water, spring water and certified reference materials could be accurately analyzed by these methods. Zhou et al. also reported a magnetic SPE method by using Fe@polyethyleneimine in combination with hydride generation atomic fluorescence spectrometry (HGAFS) for arsenic adsorption and detection, which enabled HGAFS to accurately analyze the arsenic in river water, reservoir water and cosmetic samples [23].

According to our knowledge, bifunctional materials as adsorbents and also as GFAAS matrix modifiers for preconcentration and determination of arsenic have not been reported. Herein, $\mathrm{MgO}$ crystals were synthesized and used for arsenic adsorption, the $\mathrm{MgO}$ adsorbed with arsenic were then eluted and dissolved by nitric acid, and consequently the dissolved $\mathrm{Mg}^{2+}$ was functioned as matrix modifier for As detection by GFAAS. The primary results showed $\mathrm{MgO}$ crystals were practical for the arsenic preconcentration in real waters, and the analytical procedure were also simplified by $\mathrm{Mg}^{2+}$ performing as matrix modifier.

\section{Experimental}

\subsection{Reagents and instrumentations}

All chemicals used were at least analytical grade. De-ionized water (18.2 $\mathrm{M} \Omega \mathrm{cm}$, Milli-Q water purification system) was used for standard reagents and sample dilutions. The standard stock solutions (1000 $\mathrm{mg} \mathrm{L}^{-1}$ ) of $\mathrm{As}(\mathrm{V})$ were prepared by $\mathrm{Na}_{3} \mathrm{AsO}_{4} \cdot 12 \mathrm{H}_{2} \mathrm{O}$ (Sigma). The $\mathrm{As}(\mathrm{V})$ standard

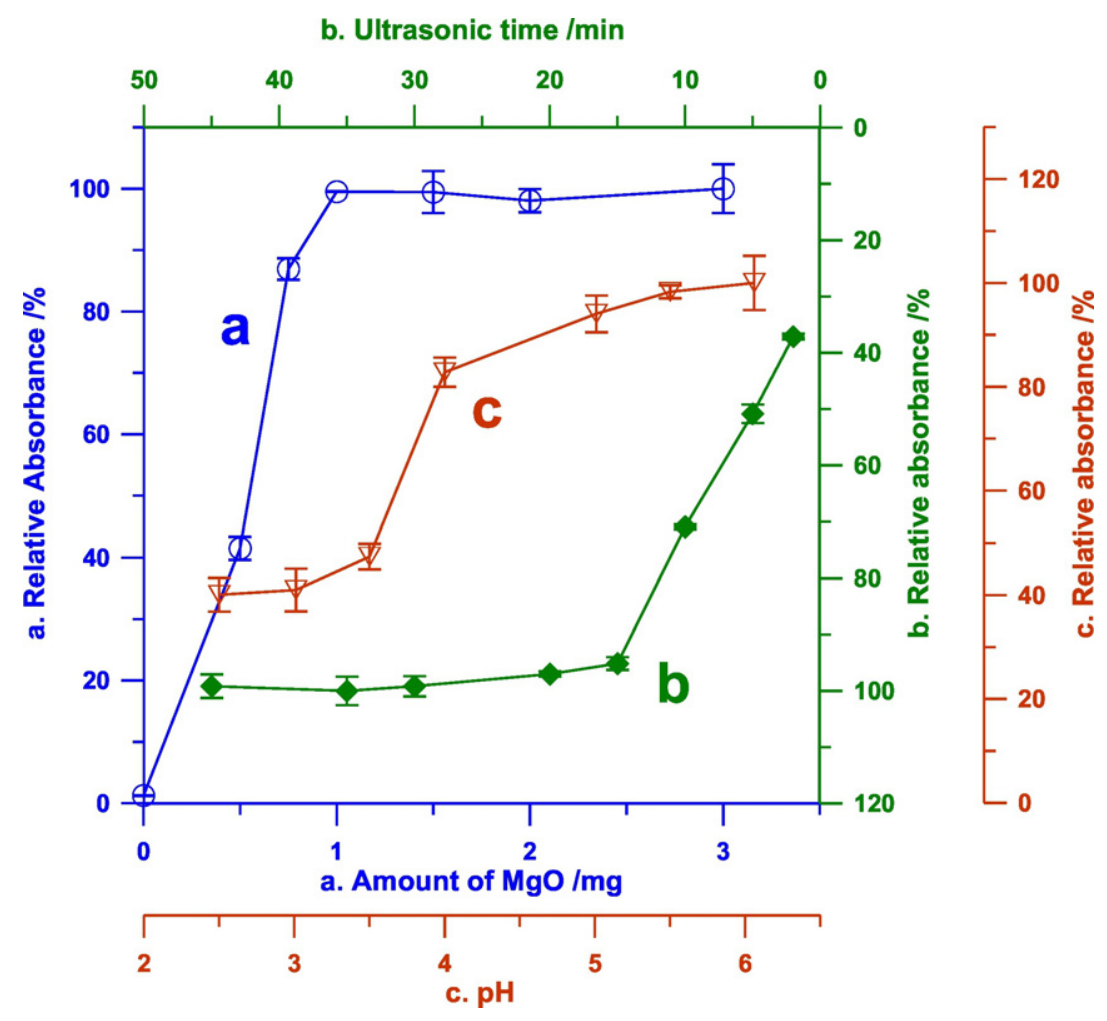

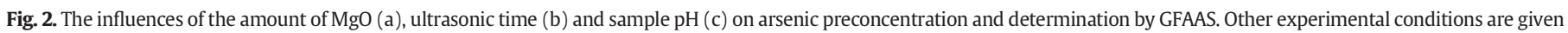
in Table 1. 
solutions used for the experimental condition optimization and calibration were prepared with appropriate dilution. Other reagents (such as $\mathrm{HNO}_{3}$, $\mathrm{Mg}\left(\mathrm{CH}_{3} \mathrm{COO}\right)_{2} \cdot 4 \mathrm{H}_{2} \mathrm{O}, \mathrm{CO}\left(\mathrm{NH}_{2}\right)_{2},\left(\mathrm{C}_{6} \mathrm{H}_{9} \mathrm{NO}\right)_{\mathrm{n}}(\mathrm{K} 90), \mathrm{C}_{2} \mathrm{H}_{5} \mathrm{OH}, \mathrm{NaCl}, \mathrm{KNO}_{3}$, $\mathrm{FeCl}_{3}, \mathrm{Ni}\left(\mathrm{NO}_{3}\right)_{2} \cdot 4 \mathrm{H}_{2} \mathrm{O}, \mathrm{AlCl}_{3}, \mathrm{ZnSO}_{4}, \mathrm{KH}_{2} \mathrm{PO}_{4}, \mathrm{~Pb}\left(\mathrm{CH}_{3} \mathrm{COO}\right)_{2}, \mathrm{BaCl}_{2}, \mathrm{CaCl}_{2}$, $\mathrm{CuSO}_{4} \cdot 5 \mathrm{H}_{2} \mathrm{O}$ and $\mathrm{AgNO}_{3}$ ) used in this study were all purchased from Sinopharm Chemical Reagent Co. Ltd. (Shanghai, China).

The quantification of As(V) was facilitated by a HITACHI Z-5700 atomic absorption spectrophotometer (Hitachi High-Technologies, Japan). A single computer was used to control the atomic absorption spectrometer. The temperature program was set as same as references [44,45]. A KQ50DE ultrasonic cleaner (Kunshan Ultrasonic Instruments Co. Ltd., China, www.ks-csyq.com/cn/index.aspx) was employed for adsorbents dispersal, and a Universal 320R centrifuge (Huayue Co. Ltd., China, www.huayueco.com) was used for separation of the adsorbents and the water in this study. A PHS-3C pH meter (Shanghai INESA Scientific Instrument Co. Ltd., China, www.lei-ci.com/products) was used to measure $\mathrm{pH}$ values. A FA2204B analytical balance (readability $0.1 \mathrm{mg}$, Shenzhen Right Era Industry Co. Ltd., China, www.yoyitime.com) was used for weighting of standard reagents and correcting of the pipets. The SXL-1216 Muffle furnace (Shenzhen Right Era Industry Co. Ltd., China, www.yoyitime. $\mathrm{com}$ ) was used to roast the $\mathrm{MgO}$ precursor. The microstructure details of $\mathrm{MgO}$ crystals were investigated by scanning electron microscopy (SEM; model SU8000, Tokyo, Japan) at an acceleration voltage of $50 \mathrm{kV}$. The obtained $\mathrm{MgO}$ was also characterized by X-ray diffraction (XRD) (a Siemens D5000 X-ray powder diffractometer) with $\mathrm{Cu} \mathrm{K} \alpha$ radiation and canned from $3^{\circ}$ and $90^{\circ}(\lambda=0.1542 \mathrm{~nm})$. The scan speed was $5^{\circ} / \mathrm{min}$. The X-ray tube was set at $100 \mathrm{~mA}$ and $40 \mathrm{kV}$ at room temperature. The obtained product was identified by comparing with the Join Committee of the Powder Diffraction Standard (JPDS) cards.

\subsection{Synthesis of $\mathrm{MgO}$ crystal}

$\mathrm{MgO}$ crystals were synthesized following the polymer template method [46,47]. Briefly, $50 \mathrm{~mL}$ of $0.4 \mathrm{~mol} \mathrm{~L}-1 \mathrm{Mg}\left(\mathrm{CH}_{3} \mathrm{COO}\right)_{2} \cdot 4 \mathrm{H}_{2} \mathrm{O}$ and $50 \mathrm{~mL}$ of $0.6 \mathrm{~mol} \mathrm{~L}^{-1} \mathrm{CO}\left(\mathrm{NH}_{2}\right)_{2}$ were prepared in de-ionized water, respectively. The $\mathrm{CO}\left(\mathrm{NH}_{2}\right)_{2}$ was added into the $\mathrm{Mg}\left(\mathrm{CH}_{3} \mathrm{COO}\right)_{2}$ solution by droplets in $5 \mathrm{~min}$, then the PVP ( $0.20 \mathrm{~g}$ ) polymer as template was added into the solution while stirring at room temperature for another $5 \mathrm{~min}$. The mixed solution was transferred to the Teflon-lined autoclave in equal phase reactor at $150{ }^{\circ} \mathrm{C}$ for $12 \mathrm{~h}$. After being cooled down to room temperature, the crude products were collected by vacuum filter and washed with de-ionized water and ethanol. The obtained products were put in vacuum drying oven at $55^{\circ} \mathrm{C}$ for $12 \mathrm{~h}$, followed by calcination for $1 \mathrm{~h}$ at $600{ }^{\circ} \mathrm{C}$ to produce $\mathrm{MgO}$ crystals.

\subsection{Arsenic preconcentration and determination}

Before the preconcentration, the water samples were filtrated through $0.22 \mu \mathrm{m}$ membrane filters and the filtrates were diluted appropriately when needed. $4.0 \mathrm{~mL}$ of the diluted water sample was pipetted into a $5 \mathrm{~mL}$ of centrifuge tube and mixed with $1.5 \mathrm{mg}$ of $\mathrm{MgO}$ crystals. The mixtures were placed in the ultrasonic bath for $15 \mathrm{~min}$, and then the mixtures were separated by the high speed centrifuge at $10,000 \mathrm{rpm}$ for $5 \mathrm{~min}$. The supernatants were poured away carefully, and the deposits were dissolved in $100 \mu \mathrm{L}$ of $\mathrm{HNO}_{3}\left(1 \mathrm{~mol} \mathrm{~L}^{-1}\right)$. The final solutions were transferred into the sharp-bottomed vessel of GFAAS auto sampler for arsenic detection.

\section{Results and discussion}

\subsection{Characterization of the synthesized $\mathrm{MgO}$ particles}

The microstructure of the $\mathrm{MgO}$ crystal was characterized by the scanning electron microscopy (SEM). The SEM image is shown in Fig. 1a. The MgO crystals were well-distributed, with the length was about $500 \mathrm{~nm}$, and diameter ranged from 100 to $200 \mathrm{~nm}$. The particle size of
Table 1

The optimized experimental conditions for arsenic preconcentration by MgO crystals.

\begin{tabular}{lll}
\hline Experimental conditions & Parameter (unit) & Value \\
\hline Sample & Volume $(\mathrm{mL})$ & 4.0 \\
& $\mathrm{pH}$ & 5.0 \\
$\mathrm{MgO}$ & Amount $(\mathrm{mg})$ & 1.5 \\
Nitric acid & Concentration $\left(\mathrm{mol} \mathrm{L}^{-1}\right)$ & 1.0 \\
& Volume $(\mu \mathrm{L})$ & 100 \\
Ultrasonic dispersing & Time $(\mathrm{min})$ & 15 \\
Centrifuge & Rotation rate $(\mathrm{rpm})$ & 10,000 \\
& Time $(\min )$ & 5 \\
\hline
\end{tabular}

the MgO crystal particle indicates it could be easily separated by the centrifuge after adsorbing the arsenic in water samples.

The crystal structure of the MgO crystal was investigated by X-ray powder diffraction (Fig. 1b). A wide-angle XRD pattern of the particle was attributed to the cubic symmetry of MgO (JCPDS card no. 741225). As illustrated in Fig. 1b, this XRD pattern confirmed that the $\mathrm{MgO}$ crystals were highly crystalline. All the obtained Bragg reflection peaks are same as the pure cubic phase of MgO crystal (JCPDS Card No. 71-1176, MgO). The five reflection peaks shown in Fig. 1b were indexed to the (1 111 ), (2 00 ), (2 200$),\left(\begin{array}{lll}3 & 1 & 1\end{array}\right)$ and (2 22 2) diffraction planes and no obvious impure peaks were observed. These results confirmed the high purity of $\mathrm{MgO}$ was synthesized.

\subsection{Optimization of the experimental conditions}

The experimental conditions for arsenic preconcentration, including amount of $\mathrm{MgO}$ crystals, ultrasonic dispersing time and sample $\mathrm{pH}$, were investigated in detail. The results of these parametric influences are summarized in Fig. 2.

Because of the adsorption efficiency of the target analytes directly relates to the amount of the adsorbents, the amount of MgO crystals for the arsenic adsorption was tested. The results are shown in Fig. 2a, by gradually increasing the amount of $\mathrm{MgO}$ from 0 to $1 \mathrm{mg}$, the received absorbance values of GFAAS for arsenic detections are significantly raised, which indicates less than $1 \mathrm{mg}$ of $\mathrm{MgO}$ is insufficient for arsenic adsorption in $4 \mathrm{~mL}$ of water samples. While, more than $1 \mathrm{mg}$ of $\mathrm{MgO}$ is used, the absorbance values are keeping around the highest level. Therefore, in order to ensure the adsorption efficiency, $1.5 \mathrm{mg}$ of $\mathrm{MgO}$ was selected for the following experiments.

The ultrasonic time of $\mathrm{MgO}$ crystals dispersing in the water samples for adsorbing the arsenic also influences the final preconcentration

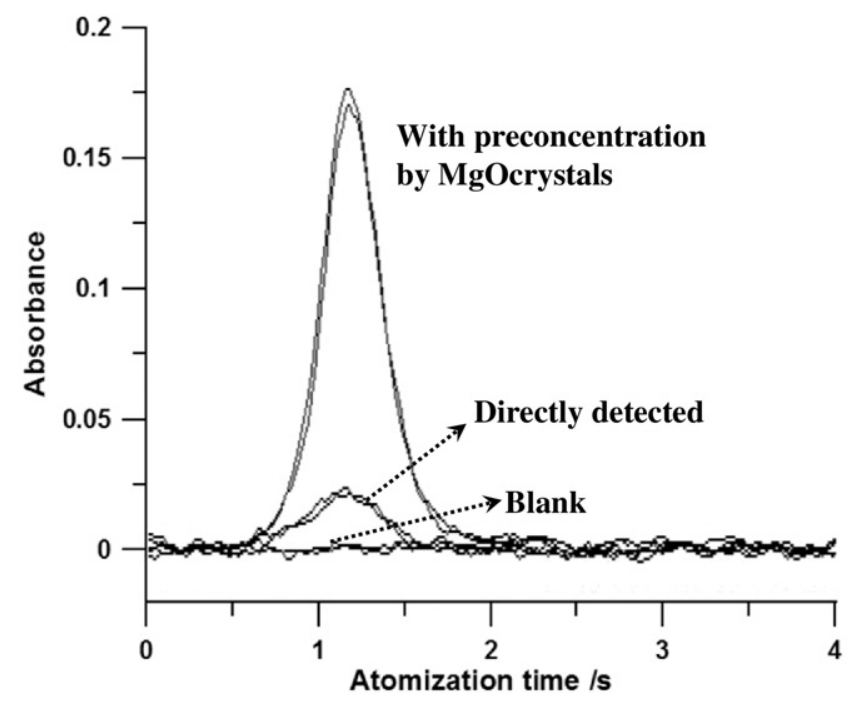

Fig. 3. The recorded GFAAS signals for $5 \mu \mathrm{g} \mathrm{L}^{-1}$ of As with preconcentration by the $\mathrm{MgO}$ crystals and detected directly. The experimental parameters are given in Table 1. 
Table 2

The determination of As in certified reference water (GBW08605), lake water, snow water and tap water sample.

\begin{tabular}{|c|c|c|c|c|c|}
\hline Samples & Certified $\left(\mu \mathrm{g} \mathrm{L}^{-1}\right)$ & Found $\left(\mu \mathrm{g} \mathrm{L}^{-1}\right)$ & Spiked $\left(\mu \mathrm{g} \mathrm{L}^{-1}\right)$ & Spiked found $\left(\mu \mathrm{g} \mathrm{L}^{-1}\right)$ & Recovery (\%) \\
\hline GBW08605 & $500 \pm 8$ & $494 \pm 15$ & & & \\
\hline Lake water & & $0.31 \pm 0.10$ & 2.0 & $2.28 \pm 0.15$ & 98.5 \\
\hline Snow water & & $0.26 \pm 0.12$ & 2.0 & $2.32 \pm 0.15$ & 103.0 \\
\hline Tape water & & n.d. ${ }^{*}$ & 2.0 & $2.01 \pm 0.07$ & 100.5 \\
\hline
\end{tabular}

n.d.*: not detected.

results. Therefore, the ultrasonic time from 2 to 40 min were tested in this study. The results of the ultrasonic time effecting the absorbance values for arsenic detection by GFAAS are shown in Fig. 2b. It is obvious that the arsenic absorbance improved along with the ultrasonic time extended, especially in 2-15 min. In 15-40 min, the detected arsenic signals increase slightly. As combining the analytical time costs and the method sensitivity, 15 min of ultrasonic time for MgO dispersing in water samples was chosen for the further experiments.

The high acidity of the water sample might cause the MgO dissolving when adding the MgO for adsorption, which would result in arsenic running away and insufficient arsenic adsorption. However, the high alkalinity of the water sample might result in co-precipitating. As a result, the sample pHs from 2 to 6 were investigated in this work. The influence of the $\mathrm{pH}$ values on the arsenic preconcentration are shown in Fig. 2c. It clearly indicates that the arsenic absorbance signals obtained at the $\mathrm{pH}$ of 5.0 and 6.0 are higher than the signals at other pHs. This phenomenon could be attributed to the electrostatic attractions between $\mathrm{MgO}$ and the arsenic species. Because of the hydrolysis of As(V) follows the Eqs. (1)-(3), at the sample $\mathrm{pH}$ of around 5.0 and 6.0, the aqueous $\mathrm{As}(\mathrm{V})$ dominated as $\mathrm{H}_{2} \mathrm{AsO}_{4}^{-}$and $\mathrm{HAsO}_{4}^{2-}$, which are easier adsorbed by the $\mathrm{MgO}$ than $\mathrm{H}_{3} \mathrm{AsO}_{4}$. Considering the $\mathrm{pH}$ values of the real water samples in nature, $\mathrm{pH}$ of 5.0 was selected for the arsenic adsorption.

Other experimental conditions, such as sample volume, centrifuge rotation rate, centrifugal time, nitric acid concentration and volume were also studied. The optimized experimental conditions are summarized in Table 1.

$$
\begin{aligned}
& \mathrm{H}_{3} \mathrm{AsO}_{4}+\mathrm{H}_{2} \mathrm{O} \Leftrightarrow \mathrm{H}_{2} \mathrm{AsO}_{4}{ }^{-}+\mathrm{H}_{3} \mathrm{O}^{+} \quad p \mathrm{Ka}_{1}=2.19 \\
& \mathrm{H}_{2} \mathrm{AsO}_{4}{ }^{-}+\mathrm{H}_{2} \mathrm{O} \Leftrightarrow \mathrm{HAsO}_{4}{ }^{2-}+\mathrm{H}_{3} \mathrm{O}^{+} \quad p \mathrm{Ka}_{2}=6.94 \\
& \mathrm{HAsO}_{4}{ }^{2-}+\mathrm{H}_{2} \mathrm{O} \Leftrightarrow \mathrm{AsO}_{4}{ }^{{ }^{-}}+\mathrm{H}_{3} \mathrm{O}^{+} \quad p \mathrm{Ka}_{3}=11.50
\end{aligned}
$$

\subsection{Interference of coexisting inorganic ions}

Considering the potential coexisting ions in nature water, the interference of ions such as alkali metal ions, alkaline earth metal ions, transition metal ions and common anions, were tested by gradually increasing their amount into arsenic standard solution for preconcentration and detection. The experimental results showed that $3000 \mathrm{mg} \mathrm{L}^{-1}$ of $\mathrm{Na}^{+}$and $\mathrm{Cl}^{-} ; 1500 \mathrm{mg} \mathrm{L}^{-1}$ of $\mathrm{K}^{+}, \mathrm{PO}_{4}^{3-}, \mathrm{NO}_{3}^{-}$and $\mathrm{SO}_{4}^{2-} ; 500 \mathrm{mg} \mathrm{L}^{-1}$ of $\mathrm{Ca}^{2+} ; 100 \mathrm{mg} \mathrm{L}^{-1}$ of $\mathrm{Zn}^{2+}, \mathrm{Ni}^{2+}, \mathrm{Al}^{3+}$ and $\mathrm{Ba}^{2+} ; 50 \mathrm{mg} \mathrm{L}^{-1}$ of $\mathrm{Cu}^{2+}, \mathrm{Pb}^{2+}$ and $\mathrm{Ag}^{+} ; 30 \mathrm{mg} \mathrm{L}^{-1}$ of Fe${ }^{3+}$ did not interfere with $5 \mu \mathrm{g} \mathrm{L}^{-1}$ of $\mathrm{As}(\mathrm{V})$ detection (within a $5 \%$ error range). For environmental water samples, especially the drinking water samples, the contents of the above species will not exceed the tolerant concentration levels, therefore, the present procedure can be directly employed, and no further treatment or masking reagents are needed for arsenic detection.

\subsection{Analytical performance}

Under the optimized experimental conditions, the MgO crystals for arsenic preconcentration achieved an enrichment factor of 13.0, and the limit of detection of GFAAS for arsenic detection was improved to $0.087 \mu \mathrm{g} \mathrm{L}^{-1}$, and the linear range was extended to 20 $\mu \mathrm{g} \mathrm{L}^{-1}$ of As. The relative standard deviation (RSD) for seven successive preconcentration and determinations of $2 \mu \mathrm{g} \mathrm{L} \mathrm{L}^{-1}$ aqueous arsenic was $4.5 \%$.

As obviously shown in Fig. 3, the signal to noise ratio of GFAAS is significantly improved. The detected signals for $5 \mu \mathrm{g} \mathrm{L}^{-1}$ of arsenic with $\mathrm{MgO}$ crystals preconcentration were much higher than the signals detected directly by GFAAS. Comparing with the previous SPE methods in combination with GFAAS for arsenic detection, e.g. LOD of 15 [43], 20 [36,48], 4.6 [49], 5 [18], and 1.97 [32] ng L ${ }^{-1}$, RSD of 3.5\% [43,48], $3.9 \%$ [49], 3.2\% [18], 4.4\% [32] and 2.3\% [36], the sensitivity of this method is slightly lower than the reported methods, but the reproducibility is at the same level of the reported methods. As the WHO guideline for arsenic concentration in drinking water is $10 \mu \mathrm{g} \mathrm{L} \mathrm{L}^{-1}$, the present method is confidently appropriate for the arsenic detection in the drinking waters.

\subsection{Method validation and application}

The present method was validated by analyzing the arsenic content in a certificated water sample (GBW08605). The certified concentration and the analytical result are summarized in Table 2. It is obvious that the found values of As in GBW08605 were in favorable agreement with the corresponding certified values. The method was also applied to analyze the arsenic concentration in three real water samples, i.e. lake water, snow water and tap water. The results are also shown in Table 2. It shows that the arsenic concentration in tap water is below the LOD of the present method, the lake and snow water contains $0.31 \pm 0.10$ and $0.26 \pm$ $0.12 \mu \mathrm{g} \mathrm{L}^{-1}$ of arsenic, respectively. The spiking recoveries for these water samples spiked with $2 \mu \mathrm{L} \mathrm{L}^{-1}$ are in range of $98.5 \%-$ $103.0 \%$, which further indicates the method could be accurate for arsenic analysis in real water samples.

\section{Conclusions}

The MgO crystal particles were successfully synthesized and performed as the bifunctional adsorbents for arsenic preconcentration and determination. With the primary investigation, the MgO crystals were appropriate for trace arsenic preconcentration in various real water samples. Sequentially with the nitric acid elution, the concentrated arsenic and the $\mathrm{Mg}^{2+}$ were transferred into GFAAS for arsenic determination without other matrix modifiers needed. The method proposed a new strategy for preconcentration and determination of arsenic by SPE in combination with GFAAS, which might have great usage in drinking water analysis in developing countries.

\section{Acknowledgement}

This work is supported by the Natural Science Foundation of China (No. 21407086, 21607161), Doctor Fund of Qingdao Agricultural University (No. 63311330, 6631112303), State Key Laboratory of Environmental Chemistry and Ecotoxicology, Research Center for Eco-Environmental Sciences, Chinese Academy of Sciences (KF2015-10). 


\section{References}

[1] P.L. Smedley, D.G. Kinniburgh, A review of the source, behaviour and distribution of arsenic in natural waters, Appl. Geochem. 17 (2002) 517-568.

[2] L. Rodriguez-Lado, G. Sun, M. Berg, Q. Zhang, H. Xue, Q. Zheng, C.A. Johnson, Groundwater arsenic contamination throughout China, Science 341 (2013) 866-868.

[3] P.K. Dasgupta, Special issue: ARSENIC, analytical chemistry and beyond... - editorial, Talanta 58 (2002) 1-2.

[4] A.H. Smith, M.M.H. Smith, Arsenic drinking water regulations in developing countries with extensive exposure, Toxicology 198 (2004) 39-44.

[5] T. Yoshida, H. Yamauchi, G.F. Sun, Chronic health effects in people exposed to arsenic via the drinking water: dose-response relationships in review, Toxicol. Appl. Pharm. 198 (2004) 243-252.

[6] M.M. Rahman, U.K. Chowdhury, S.C. Mukherjee, B.K. Mondal, K. Paul, D. Lodh, B.K. Biswas, C.R. Chanda, G.K. Basu, K.C. Saha, S. Roy, R. Das, S.K. Palit, Q. Quamruzzaman, D. Chakraborti, Chronic arsenic toxicity in Bangladesh and West Bengal, India - a review and commentary, J. Toxicol.-Clin. Toxic. 39 (2001) 683-700.

[7] K. Jomova, Z. Jenisova, M. Feszterova, S. Baros, J. Liska, D. Hudecova, C.J. Rhodes, M. Valko, Arsenic: toxicity, oxidative stress and human disease, J. Appl. Toxicol. 31 (2011) 95-107.

[8] World Health Organization, Guidelines for Drinking-water Quality - 4th ed, http:// www.who.int/water_sanitation_health/dwq/guidelines/en/ 2011.

[9] B.K. Mandal, K.T. Suzuki, Arsenic round the world: a review, Talanta 58 (2002) 201-235.

[10] M.-L. Chen, L.-Y. Ma, X.-W. Chen, New procedures for arsenic speciation: a review, Talanta 125 (2014) 78-86

[11] J. Ma, M.K. Sengupta, D. Yuan, P.K. Dasgupta, Speciation and detection of arsenic in aqueous samples: a review of recent progress in non-atomic spectrometric methods, Anal. Chim. Acta 831 (2014) 1-23.

[12] H. Shen, P.K. Dasgupta, Electrochemical arsine generators for arsenic determination, Anal. Chem. 86 (2014) 7705-7711.

[13] M.K. Sengupta, M.F. Sawalha, S.-I. Ohira, A.D. Idowu, P.K. Dasgupta, Green analyzer for the measurement of total arsenic in drinking water: electrochemical reduction of arsenate to arsine and gas phase chemiluminescence with ozone, Anal. Chem. 82 (2010) 3467-3473.

[14] J. Cui, J. Shi, G. Jiang, C. Jing, Arsenic levels and speciation from ingestion exposures to biomarkers in Shanxi, China: implications for human health, Environ. Sci. Technol. 47 (2013) 5419-5424.

[15] A.J. Bednar, J.R. Garbarino, J.F. Ranville, T.R. Wildeman, Preserving the distribution of inorganic arsenic species in groundwater and acid mine drainage samples, Environ. Sci. Technol. 36 (2002) 2213-2218.

[16] X.P. Yan, M. Sperling, B. Welz, On-line coupling of flow injection microcolumn separation and preconcentration to electrothermal atomic absorption spectrometry for determination of (ultra)trace selenite and selenate in water, Anal. Chem. 71 (1999) 4353-4360.

[17] P. Liang, R. Liu, Speciation analysis of inorganic arsenic in water samples by immobilized nanometer titanium dioxide separation and graphite furnace atomic absorption spectrometric determination, Anal. Chim. Acta 602 (2007) 32-36.

[18] M. Shirani, A. Semnani, S. Habibollahi, H. Haddadi, Ultrasound-assisted, ionic liquidlinked, dual-magnetic multiwall carbon nanotube microextraction combined with electrothermal atomic absorption spectrometry for simultaneous determination of cadmium and arsenic in food samples, J. Anal. Atom. Spectrom. 30 (2015) 1057-1063.

[19] X.P. Yan, X.B. Yin, X.W. He, Y. Jiang, Flow injection on-line sorption preconcentration coupled with hydride generation atomic fluorescence spectrometry for determination of (ultra)trace amounts of arsenic(III) and arsenic(V) in natural water samples, Anal. Chem. 74 (2002) 2162-2166.

[20] Y.-L. Yu, Z. Du, M.-L. Chen, J.-H. Wang, Coating of a thin layer of $\mathrm{NaBH}_{4}$ solution for mercury vapor generation coupled to atomic fluorescence spectrometry, J. Anal. Atom. Spectrom. 22 (2007) 800-806.

[21] C.-G. Yuan, K. Zhang, Z. Wang, G. Jiang, Rapid analysis of volatile arsenic species released from lake sediment by a packed cotton column coupled with atomic fluorescence spectrometry, J. Anal. Atom. Spectrom. 25 (2010) 1605-1611.

[22] M.-L. Chen, Y. Sun, C.-B. Huo, C. Liu, J.-H. Wang, Akaganeite decorated graphene oxide composite for arsenic adsorption/removal and its proconcentration at ultratrace level, Chemosphere 130 (2015) 52-58.

[23] Q.X. Zhou, Z.W. Zheng, J.P. Xiao, H.L. Fan, Sensitive determination of As (III) and As (V) by magnetic solid phase extraction with Fe@polyethyleneimine in combination with hydride generation atomic fluorescence spectrometry, Talanta 156 (2016) 196-203.

[24] B. Chen, B. Hu, M. He, X. Mao, W. Zu, Synthesis of mixed coating with multi-functional groups for in-tube hollow fiber solid phase microextraction-high performance liquid chromatography-inductively coupled plasma mass spectrometry speciation of arsenic in human urine, J. Chromatogr. A 1227 (2012) 19-28.

[25] L. Liu, Z. Yun, B. He, G. Jiang, Efficient Interface for online coupling of capillary electrophoresis with inductively coupled plasma-mass spectrometry and its application in simultaneous speciation analysis of arsenic and selenium, Anal. Chem. 86 (2014) $8167-8175$.

[26] X.P. Yan, R. Kerrich, M.J. Hendry, Determination of (ultra)trace amounts of arsenic(III) and arsenic(V) in water by inductively coupled plasma mass spectrometry coupled with flow injection on-line sorption preconcentration and separation in a knotted reactor, Anal. Chem. 70 (1998) 4736-4742.

[27] D.Q. Hung, O. Nekrassova, R.G. Compton, Analytical methods for inorganic arsenic in water: a review, Talanta 64 (2004) 269-277.

[28] R.A. Gil, P.H. Pacheco, S. Cerutti, L.D. Martinez, Vapor generation - atomic spectrometric techniques. Expanding frontiers through specific-species preconcentration. A review, Anal. Chim. Acta 875 (2015) 7-21.

[29] K.A. Francesconi, D. Kuehnelt, Determination of arsenic species: a critical review of methods and applications, 2000-2003, Analyst 129 (2004) 373-395.

[30] F. Shemirani, M. Baghdadi, M. Ramezani, Preconcentration and determination of ultra trace amounts of arsenic(III) and arsenic(V) in tap water and total arsenic in biological samples by cloud point extraction and electrothermal atomic absorption spectrometry, Talanta 65 (2005) 882-887.

[31] M. Shamsipur, N. Fattahi, Y. Assadi, M. Sadeghi, K. Sharafi, Speciation of As(III) and As(V) in water samples by graphite furnace atomic absorption spectrometry after solid phase extraction combined with dispersive liquid-liquid microextraction based on the solidification of floating organic drop, Talanta 130 (2014) 26-32.

[32] S. Hassanpoor, G. Khayatian, A.R.J. Azar, Ultra-trace determination of arsenic species in environmental waters, food and biological samples using a modified aluminum oxide nanoparticle sorbent and AAS detection after multivariate optimization, Microchim. Acta 182 (2015) 1957-1965.

[33] R.E. Rivas, I. Lopez-Garcia, M. Hernandez-Cordoba, Speciation of very low amounts of arsenic and antimony in waters using dispersive liquid-liquid microextraction and electrothermal atomic absorption spectrometry, Spectrochim. Acta B 64 (2009) 329-333.

[34] Y. Liu, M. He, B. Chen, B. Hu, Simultaneous speciation of inorganic arsenic, selenium and tellurium in environmental water samples by dispersive liquid liquid microextraction combined with electrothermal vaporization inductively coupled plasma mass spectrometry, Talanta 142 (2015) 213-220.

[35] R.P. Monasterio, R.G. Wuilloud, Ionic liquid as ion-pairing reagent for liquid-liquid microextraction and preconcentration of arsenic species in natural waters followed by ETAAS, J. Anal. At. Spectrom. 25 (2010) 1485-1490.

[36] J.A. Baig, T.G. Kazi, A.Q. Shah, M.B. Arain, H.I. Afridi, G.A. Kandhro, S. Khan, Optimization of cloud point extraction and solid phase extraction methods for speciation of arsenic in natural water using multivariate technique, Anal. Chim. Acta 651 (2009) 57-63.

[37] S. Li, M. Wang, Y.Zhong, Z. Zhang, B. Yang, Cloud point extraction for trace inorganic arsenic speciation analysis in water samples by hydride generation atomic fluorescence spectrometry, Spectrochim. Acta B 111 (2015) 74-79.

[38] R.A. Gil, N. Ferrua, J.A. Salonia, R.A. Olsina, L.D. Martinez, On-line arsenic co-precipitation on ethyl vinyl acetate turning-packed mini-column followed by hydride generation-ICP OES determination, J. Hazard. Mater. 143 (2007) 431-436.

[39] R. Liu, P. Wu, M. Xi, K. Xu, Y. Lv, Inorganic arsenic speciation analysis of water samples by trapping arsine on tungsten coil for atomic fluorescence spectrometric determination, Talanta 78 (2009) 885-890.

[40] A. Maratta, M. Acosta, L.D. Martinez, P.H. Pacheco, R.A. Gil, Ultratrace arsenic determination through hydride trapping on oxidized multiwall carbon nanotubes coupled to electrothermal atomic absorption spectrometry, J. Anal. Atom. Spectrom. 28 (2013) 916-922.

[41] N.B. Ivanenko, N.D. Solovyev, A.A. Ivanenko, D.V. Navolotskii, Biological monitoring of arsenic pollution based on whole blood arsenic atomic absorption assessment with in situ hydride trapping, J. Anal. Atom. Spectrom. 29 (2014) 1850-1857.

[42] M. Chen, Y. Lin, C. Gu, J. Wang, Arsenic sorption and speciation with branchpolyethyleneimine modified carbon nanotubes with detection by atomic fluorescence spectrometry, Talanta 104 (2013) 53-57.

[43] M.-L. Chen, C.-B. Gu, T. Yang, Y. Sun, J.-H. Wang, A green sorbent of esterified eggshell membrane for highly selective uptake of arsenate and speciation of inorganic arsenic, Talanta 116 (2013) 688-694.

[44] Y. Tian, M.-L. Chen, X.-W. Chen, J.-H. Wang, Y. Hirano, H. Sakamoto, I. Setsu, Arsenic speciation with gradient hydride generation interfacing liquid chromatography and atomic absorption spectrometry, J. Anal. Atom. Spectrom. 25 (2010) 48-54

[45] Y. Tian, M.-L. Chen, X.-W. Chen, J.-H. Wang, Y. Hirano, H. Sakamoto, T. Shirasaki, Arsenic preconcentration via solid phase extraction and speciation by HPLC-gradient hydride generation atomic absorption spectrometry, J. Anal. Atom. Spectrom. 26 (2011) 133-140

[46] S.-W. Bain, Z. Ma, Z.-M. Cui, L.-S. Zhang, F. Niu, W.-G. Song, Synthesis of micrometersized nanostructured magnesium oxide and its high catalytic activity in the ClaisenSchmidt condensation reaction, J. Phys. Chem. C 112 (2008) 11340-11344.

[47] F. Al-Hazmi, F. Alnowaiser, A.A. Al-Ghamdi, A.A. Al-Ghamdi, M.M. Aly, R.M. AlTuwirqi, F. El-Tantawy, A new large-scale synthesis of magnesium oxide nanowires: structural and antibacterial properties, Superlattices Microst. 52 (2012) 200-209.

[48] I. Lopez-Garcia, R.E. Rivas, M. Hernandez-Cordoba, Use of carbon nanotubes and electrothermal atomic absorption spectrometry for the speciation of very low amounts of arsenic and antimony in waters, Talanta 86 (2011) 52-57.

[49] H. Abdolmohammad-Zadeh, A. Jouyban, R. Amini, Ultratrace determination of arsenic in water samples by electrothermal atomic absorption spectrometry after preconcentration with $\mathrm{Mg}-\mathrm{Al}-\mathrm{Fe}$ ternary layered double hydroxide nano-sorbent, Talanta 116 (2013) 604-610. 